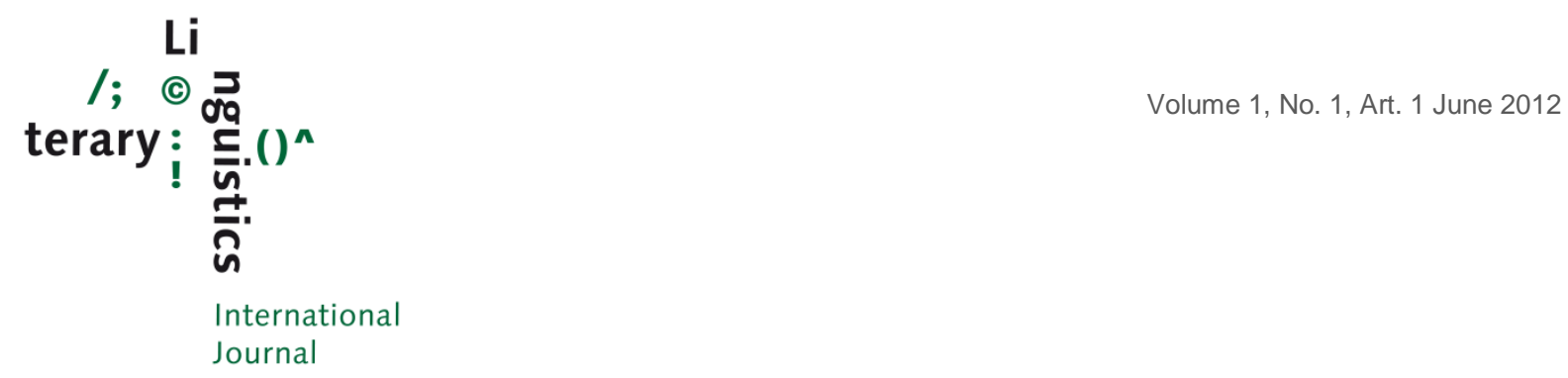

\title{
Instead of an Editorial: Mission Statements by Representatives of Both Fields
}

\author{
Anja Müller-Wood, Anneli Sarhimaa and others
}

Keywords:

Literature; linguistics; metrics; narratology; stylistics; cognitive approaches to language and literature

\begin{abstract}
The following mission statements by linguists and literary scholars working in different institutional and cultural contexts and at different stages of their careers are intended to map out the terrain covered by this journal. They tell similar stories about how these scholars came to cross the disciplinary boundary that too often divides their two fields, and they reveal a number of shared interests and emphases. But they also highlight the diversity of methodologies to which this journal is open - from metrics and stylistics to the cognitive sciences and Systemic Functional Grammar. The hopes and expectations voiced by the authors are partly pragmatic, expressing the wish that the journal's Open Access format will have a broader reach than a journal published in the "traditional" way would, notably to colleagues outside of Western Europe. They also, however, emphasise the journal's potential to shape our conception of "literary linguistics" and, therefore, to make an innovative contribution to shaping what continues to be a contested and often misunderstood "field".
\end{abstract}

\section{Introduction}

The intersection of research interests that we (and others) have chosen to call "literary linguistics" is a broad area with fuzzy boundaries, covering a variety of scholarly concerns; this diversity is also illustrated by the mission statements that follow below. Written by scholars working on both sides of the disciplinary fence, in different institutional contexts and at different stages of their careers, they document both that a commitment to crossing the boundary between linguistics and literary scholarship is shared by many specialists in these respective fields and that this this interest draws on different, and not always compatible, intellectual traditions. This lack of a fixed disciplinary identity certainly causes problems, some ideological, others pragmatic: Which methods do we apply? On which points do we agree and where do we beg to differ (cf. de Beaugrande 423)? How can we integrate these potentially divergent research interests and intentions? But also, more practically: Which citation system do we follow in our publications? Who awards your degree if you study at a university where linguistics and literary studies happen to be taught in different departments?

Despite such challenges, this lack of definition may also be the field's greatest strength, a sign of its scope, and a challenge to the continuing prejudices 
against literary linguistics (which some scholars still either proclaim dead or a throwback to older forms of traditional philology). The vibrant research undertaken in recent years under this label shows not only that the reports of the field's demise are premature, but that it actually is a cutting-edge affair. Literary linguistics is simultaneously a direct consequence of the fundamental shift in the humanities during recent decades from purely text-based to contextsensitive approaches (cf. Bernstein passim, de Beaugrande passim and Fabb and Durant passim) and a sign that this transformation is still underway. It is research pursued enthusiastically by many young scholars, be it in the context of several MAs in Literary Linguistics taught at UK universities (Birmingham, Nottingham, Sheffield, Strathclyde and Westminster), or research groups like that at Johannes Gutenberg University in Mainz (Germany), out of whose work this journal emerged. Even a brief survey of this research reveals that literary linguistics, far from an academic archaism, is indeed a dynamic and growing intellectual enterprise shared by scholars from different countries and cultures who work on a wide range of sources in a variety of languages.

One aim of this new journal is to provide a forum for debate to contribute to defining the coordinates of this vibrant and expanding field. Literary linguistics, in Nigel Fabb's words, is "the application of linguistic theory to literature" (Fabb 446), but even if today such an interdisciplinary conjunction is entirely acceptable, it continues to throw open a string of other issues. Are "ordinary" and "literary" language really "natural allies" (Fowler 11), allowing us to apply linguistic methodology straightforwardly to literature? ${ }^{1}$ And if that is the case, do we then not need to broach more fundamental questions regarding both the nature of language and of literature? How do we process language? What happens in our minds when we read a literary text? In fact: What is literature and how can linguistics help us define it?

Unsurprisingly, an important inspiration for the field of literary linguistics has come from the cognitive turn taken by humanities scholarship in the last twentyfive years. The observation that both natural and literary language possess striking regularity raises the crucial question of which aspects of this regularity are cognitive (that is, hard-wired in our brains) and which are conventional (that is, learned) (cf. Fabb 446-47). Under the influence of the cognitive sciences, scholars have begun to rethink formal and stylistic features such as metaphors and metrical patterning: Rather than taking them as ornamental surface effects deliberately deployed by authors, they increasingly agree that they are fundamental structuring principles of human cognition.

This attention to how the mind works, however, has groundbreaking implications for literary linguists' methodologies. Contemporary literary linguistics, rather than merely continuing the work of "traditional" stylistics - for instance in corpus linguistic guise (cf. Fischer-Starcke) - is therefore related to what Peter Stockwell calls "cognitive poetics", which advocates that our reading of literary texts "may be explained with reference to general human principles of linguistic and cognitive processing" (Gavins and Steen 2). While reaching back to

\footnotetext{
${ }^{1}$ For a sceptical answer to this perennially divisive question see Miall \& Kuiken.
} 
structuralist concerns with form, the emphasis of cognitive poetics is on the process of reading and the effects of language and literature: "cognitive poetics is not the study of texts alone, nor even specifically the study of literary texts; it is the study of literary reading" (Stockwell 165). In connecting the study of literature "with psychology and cognitive science in general" (Gavins and Steen 2 ), it also ties language and literature back to the world, emphasising that meaning-making is steeped in our knowledge of the world and "our embodied interaction with that world" (Gavins and Steent 9).

It is especially the issue of "embodied interaction" that needs further exploration, however much cognitive research has come to acknowledge the physical basis of mental processes. Cognitive approaches have increasingly moved away from merely descriptive perspectives to explanatory ones, yet they still need to become more explicit in defining and explaining the precise nature of the embodiment that they presume. It is not least as regards this point that we hope this journal will leave its very own mark and distinguish itself from other existing publications, notably The Poetics and Linguistics Association's Journal Language and Literature and The Journal of Literary Semantics. The aim of the International Journal of Literary Linguistics is not to compete with or replace these existing outlets of literary linguistic research, but to offer its own, distinctive perspective along the cognitive lines outlined above. This is the first Open Access publication in the field and it is this formal feature alone that makes this journal new. Over and above this, our aim is to raise awareness not only of the existence of literary linguistics, but also to highlight its diversity as well as of the innovative quality of the research undertaken under this name.

\section{Views from both sides of the disciplinary fence}

\section{Monika Fludernik, Freiburg:}

The linguistic analysis of literary texts has a long tradition. As a narratologist, I became acquainted with what was then called "linguistic approaches to literature" or "stylistics" (at least in Stanley Fish's critique of it) through the work of Roman Jakobson. Russian formalism was part of my narratological training. I studied at Graz, where Professor Stanzel kept referring to Shklovsky and Jakobson and Mukarovsky as he expounded on Dickens or the eighteenthcentury novel or modern poetry.

Since I ended up writing a $\mathrm{PhD}$ thesis on narrative and dialogue in James Joyce's Ulysses, I naturally concentrated very much on the textual surface, on speech and thought representation and issues of deixis and tense. As a result, I found myself getting more and more involved in stylistic issues, and hence in literary linguistics. Having had a very sound linguistic training at my university, with a thorough immersion into both historical linguistics (I did a seminar on Beowulf and read the whole of the Canterbury Tales) and modern linguistics (I delighted in Chomsky's theory), I was sufficiently into formal linguistics to find stylistics very attractive as an approach. 
In my second book, The Fictions of Language and the Languages of Fiction, which was my Habilitation thesis, I then broadened my perspective to include English-language texts from the Middle Ages to the present and also looked at conversational narrative. Thematically, I narrowed my analysis to speech and thought representation, especially the form of free indirect discourse. Since this book engaged in a serious debate with Ann Banfield, it also required extensive linguistic analysis. I was therefore doing narratology in the guise of literary linguistics or literary linguistics with an emphasis on narratology.

In Fictions of Language and then more prominently in Towards a 'Natural' Narratology I also turned more and more to cognitive paradigms, an interest that I have been expanding (most recently in Beyond Cognitive Metaphor Theory). I read a good deal of cognitive linguistics, even subscribed to the journal Cognitive Linguistics for several years, and was fascinated with Wolfgang Dressler's Natürlichkeitstheorie. I also became involved in the International Association of Literary Semantics and served as its president for eight years.

Thus the question of how I got into literary linguistics really cannot be answered by reference to a kind of epiphany, but to a process of combined interests in narrative and linguistics merging into what then was a field that I encountered existed already.

My inspiration in the realm of literary linguistics has come mostly from British scholars, especially Michael H. Short, Roger Sell, Michael Toolan and Elena Semino, but there are of course numerous other colleagues whose work I greatly appreciate.

As to my expectations of the journal: Publishing online is a way of publishing faster and getting to more people. There are many scholars out there, especially in the countries from the former Eastern Bloc, who are interested in literary linguistics. And thanks to the net, it is possible to reach an audience at the other end of the world, in India, Australia or in Argentina. What I see as the greatest challenge of the journal will be to find a profile that makes it distinct from the Journal of Literary Semantics on the one hand and Language and Literature on the other, these two publications being the standard journals for literary linguistic work at the moment.

\section{Satu Grünthal, Helsinki:}

I am a literary critic, and my own special field of interest is poetry. Poetry is a genre highly aware of and dependent on structure, rhythm and versification, and to study poetry without taking these linguistic elements into consideration would be a contradiction, at least for me. As a student, I studied both literary criticism and linguistics, and the field where I felt I could most fruitfully combine my main interest, poetry, with these two academic approaches was the study of metrics. A couple of decades passed spent mainly with other academic endeavours, but the past few years have brought me back to metrical research. 
Understandably, I see the study of poetry, especially of its metrics and versification, as a natural common ground of literary criticism and linguistics. The benefit is mutual: to do research on poetry without taking linguistic viewpoints into consideration would leave many of its essential features aside, but just as well would a pure linguistic analysis of poetry forget its essence as a semantically and artistically meaningful text. I welcome the foundation of the International Journal of Literary Linguistics with great pleasure. I hope the journal will serve as a meeting point for international scholars from different fields, cultural contexts and academic traditions sharing a joint interest in related themes. By doing this, the journal will also contribute to the building up of new networks of collaboration and exchange of ideas.

\section{Anja Müller-Wood, Mainz:}

I have always been fascinated by language, both by its reliable rule-boundness and its often baffling ambiguities, its powerful ability to make meaning, enable communication and help create culture, but also to act as a source of incomprehension and misunderstanding. That as a student I initially (and instinctively) turned to the study of literature, had to do with my belief that linguistics was a far too abstract and mechanistic methodology to be relevant to literature. In retrospect, this attitude appears strikingly prejudiced, though I have to say in my defence that it seems to have been fostered by all the academic contexts in which I have studied and worked. I see much of my research today as a reaction against a disciplinary division pursued by linguists and literary scholars alike, which I find increasingly counterproductive, maybe even unnatural, for it seems obvious that both fields can learn much from one another.

This conviction has to do not least with the fact that in part it was linguistics that helped me rediscover the interests that had originally drawn me to the study of literature, at a point when I had begun to be dissatisfied with the historical and theoretical turn literary scholarship (including my own) had taken, and which seemed to have moved me away from my original interest in how literature works. Linguistic methodology can help corroborate literary scholars' intuitive responses to texts by providing them with systematic explanatory models, and I have found it especially relevant when it comes to the understanding of the reception of literature, the issue that has increasingly occupied me in recent years. Here, the encounter with cognitive linguistics has been particularly influential, drawing my attention to entirely new scientific frameworks with which to approach literature. In recent years, the cognitive and neurosciences have gathered an impressive body of work that has brought us closer than ever in human history to answering the question of how the mind works (and therefore what makes us human). This knowledge is essential to our discussion of language, communication and culture, whether approached from a linguistic or literary perspective, and as such it is also an approach that bridges the gap between the two fields. 
Obviously, as a literary scholar, I take literature to be more than just data and to understand the meaning of literary texts it does not suffice to register what is going on the textual surface. The best literary linguists have been able to provide holistic interpretations of texts whose results are significant for both fields. Just as a linguistic perspective can draw literary scholars' attention to unconsidered aspects of literary language, so literary perspectives - the knowledge of literary concerns, strategies and methodologies - ought to help linguists formulate new questions. This is also where my greatest hopes for the journal lie, which I see as a forum for a truly integrated, interdisciplinary literary linguistics, which endeavours to do justice to linguistics and literary studies alike.

\section{Anneli Sarhimaa, Mainz:}

I turned to the field of literary linguistics for fairly practical and prosaic reasons. As the professor of the Northern European and Baltic languages at a German university, who thinks the best way of learning to "do" linguistics is to analyse empirical material, I am constantly on the lookout for empirical data for students' seminar papers and theses which would be both easily available and appropriate to their language skills. Given my life-long love of literature in its various forms I every now and then suggested topics that could be investigated using literary works as data. So, little by little, I started to have undergraduate and post-graduate students around me whose research interests have developed in the field of the borderland between linguistics and literary studies. I also have the luck of having quite a few friends who are literary scholars and who over the years have deepened my understanding of how literature works and how it can be analysed and investigated.

The scholar whose works have been of particular significance for me in the field of literary linguistics is without any doubt Mikhail Bakhtin, but I also have received much from Vladimir Propp, M.A.K. Halliday, J.R. Martin and David Rose. Bakhtin and Propp I had already found when studying Russian language as my M.A. major at university. In the course of my career as a discourse linguist and a sociolinguist interested in naturally occurring speech, I have recurrently found Bakhtin's theories of dialogism, polyphony and the heteroglossic nature of language, as well as Propp's idea of narrative roles, very useful tools for analyzing oral, unplanned narratives. Over the years, my literarylinguistic thinking has been elaborated by Halliday and further systemicfunctional linguistics, especially Martin and Rose. I fully agree with Halliday in that language is "situated": a linguistic expression does not have a context-free meaning that would specify all its contextual uses but linguistic expressions rather consist of or contain meaning potentials which acquire their concrete meaning when used in a particular utterance. Martin and Rose, in my understanding, think in the vein I do, too, that an important dimension in analyzing utterances is to approach them as products of various voices that are linked to one another through the socially constituted fabric of language. As language does not, however, statically reflect external realities, ultimately the relationship between language and the social is dialogic in nature: language 
actively participates in shaping and reshaping social realities, including literary works, which in their turn shape language use.

My expectations of the International Journal of Literary Linguistics are high and optimistic. Today my fascination of literary linguistics is nourished by several doctoral students whose fresh and insightful research shows the endless theoretical and methodological possibilities in re-establishing the ties between the two central scholarly disciplines, linguistics and literary studies.

Consequently, I firmly believe that the new journal will offer a fertile, polyphonic and dialogic forum for discovering new aspects of the mesmerizing interplay of the human language (use) and culture in the most general sense of the terms.

\section{Julia Kind and Marie-Christine Kloes, Mainz:}

While discussing our research interests, the two of us - a graduate student of linguistics and a doctoral student of English literature - were surprised at finding a shared history: While we were students both of us had been nurturing, more or less consciously, a slight sense of reluctance to engage with our neighbouring discipline. While we were aware that "out there" might be something else, something beyond either linguistics or literary studies, something that might be rather important for our own discipline, we continued studying mainly within the boundaries of our respective subject of studies. Once we discussed what initially made us turn to the field of literary linguistics we spotted similar interests and questions. Our current projects were sparked by our fascination for the emotional and cognitive aspects of the reader's engagement with literature.

Marie-Christine researches how linguistically verifiable lexicogrammatical patterns in Swedish crime novels can evoke similar feelings across audiences. On the linguistic side Marie-Christine has primarily been influenced by M. A. K. Halliday's systemic-functional grammar theory. J. R. Martin, D. Rose and P. R. $\mathrm{R}$. White's appraisal theory attracted her attention to the analysis of readers' feelings. Within stylistics she has largely been inspired by $\mathrm{G}$. Leech and M. Short's numerous ways of interpreting literature through the analysis of lexis and grammar. Julia focuses on the relation of literature and (neuro)cognition: She researches how complex metaphors and similes are construed in narrative texts and is interested in analysing how readers can identify and understand literal and abstract meaning. Jerome A. Feldman's Neural Theory of Language, George Lakoff and Mark Johnson's conceptual metaphor theory and Lakoff's work on the embodied mind have provided her with an understanding of the brain's neural processes and their role in both the production and reception of literal and metaphorical meaning in narrative texts.

We look forward to the International Journal of Literary Linguistics as a platform for a diverse range of interdisciplinary studies; we are hoping for a journal which smoothes the way for a mutual exchange of inspiring ideas, divergent opinions and new methodologies at the interface of literary studies and linguistics. 


\section{References}

Beaugrande, Robert de (1993). Closing the Gap Between Linguistics and Literary Study: Discourse Analysis and Literary Theory, Journal of Advanced Composition 13 (2), 423-448.

Bernstein, Cynthia Goldin (1994). The Contextualization of Linguistic Criticism. The Text and Beyond: Essays in Literary Linguistics, ed. Cynthia Goldin Bernstein. Tuscaloosa AL: The University of Alabama Press, 3-14.

Fabb, Nigel (2001). Linguistics and Literature, The Handbook of Linguistics, eds. Mark Aronoff \& Janie Rees-Miller. Oxford: Blackwell, 446-65.

Fabb, Nigel and Alan Durant (1987). Introduction: The Linguistics of Writing: Retrospect and Prospect After Twenty-Five Years. The Linguistics of Writing: Arguments Between Language and Literature, eds. Nigel Fabb, Derek Attridge, Alan Durant \& Colin MacCabe. Manchester: Manchester UP, 1-14,

Fischer-Starcke, Bettina (2010). Corpus Linguistics in Literary Analysis: Jane Austen and her Contemporaries. London: Continuum.

Fowler, Roger (1971): The Languages of Literature: Some Linguistic Contributions to Criticism. London, Routledge.

Gavins, Joanna \& Steen, Gerard (2003). Contextualising Cognitive Poetics. Cognitive Poetics in Practice, eds. Joanna Gavins \& Gerard Steen. London and New York: Routledge, 1-12.

Miall, David S. \& Kuiken, Don (1994). Beyond Text Theory: Understanding Literary Response, Discourse Processes 17, 337-352.

Stockwell, Peter (2002). Cognitive Poetics: An Introduction. London and New York: Routledge. 